\title{
- Transferência de imunidade passiva colostral e a morbidade e mortalidade de bezerros neonatos
}

\section{- Morbidity and mortality of neonate calves related to immunity transfer by colostrum}

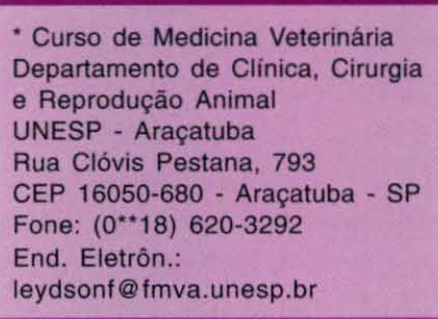

- Curso de Medicina Veterinária Departamento de Clínica, Cirurgia e Reprodução Animal UNESP - Araçatuba Rua Clóvis Pestana, 793 CEP 16050-680 - Araçatuba - SP End. Eletrôn.:

leydsonf@fmva.unesp.br

\footnotetext{
* Francisco Leydson Formiga Feitosa ${ }^{1}$ - CRMV-SP - $\mathrm{n}^{0} 5160$

Eduardo Harry Birgel ${ }^{2}$ - CRMV-SP- $\mathrm{n}^{0} 0018$

Paulo César Ciarlini ${ }^{3}$ - CRMV-SP- $\mathrm{n}^{0} \mathbf{6 7 6 7}$

Luís Cláudio NogueiraMendes ${ }^{3}$-CRMV-SP - $\mathrm{n}^{0} 6112$

Sílvia Helena Venturoli Perri ${ }^{4}$ - Matemática
}

1. Professor Assistente Doutor do Curso de Medicina Veterinária - UNESP/Araçatuba/SP.

2. Professor Titular do Departamento de Clínica Médica - FMVZ - USP/SP.

3. Professor Assistente Doutor do Curso de Medicina Veterinária - UNESP/Araçatuba/SP.

4. Professora Assistente Doutora do Curso de Medicina Veterinária - UNESP/Araçatuba/SP.

\section{RESUMO}

A morbidade e a mortalidade foram avaliadas em bezerros até os 90 dias de idade. A concentração da imunoglobulina $\mathrm{G}$, da proteína total e suas frações, bem como a atividade da gama-glutamiltransferase foram determinadas no sangue de 40 bezerros, às 24 horas de vida. Todos os animais que morreram nos primeiros três meses de idade apresentavam menores taxas de proteína total, IgG e de atividade sérica de gama-glutamiltransferase, quando comparados com os animais que sobreviveram.

Palavras-chave: imunoglobulina, bezerros, sobrevivência, colostro, proteínas séricas, GGT.

\section{Introdução}

A imediata exposição a agentes infecciosos, ao nascimento, implica em que os animais neonatos possuam um mecanismo de defesa apropriado. A imunização passiva, através da absorção de imunoglobulinas presentes no colostro, conseqüentemente, é considerada como o processo natural mais significativo para conferir uma proteção imunitária eficaz, nas fases iniciais da vida do bezerro, já que, nos bovinos, do mesmo modo que em outros ruminantes, não ocorre uma efetiva transferência transplacentária de imunoglobulinas durante a gestação, fazendo com que esses neonatos nasçam hipo ou agamaglobulinêmicos (ROBISON et al., 1988).

As primeiras 24 horas de vida representam o período de maior importância para o reconhecimento de situações que poderão gerar futuros problemas de saúde no neonato (Figura 1); intervenções oportunas, nes- 


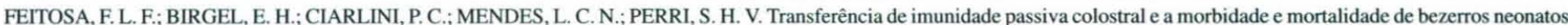

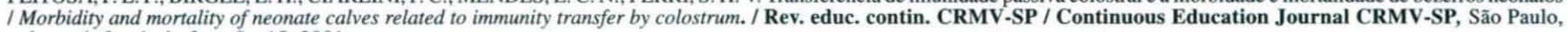
volume 4, fascículo 2, p. 9 - 15, 2001.

sa fase, podem minimizar ou prevenir futuras conseqüências negativas à higidez e à própria produtividade desses animais. Com freqüência, têm sido referidas maiores taxas de morbidade e mortalidade em bezerros neonatos que receberam uma inadequada quantidade de colostro ou cuja concentração sérica de imunoglobulinas é menor do que a concentração sérica considerada padrão para a espécie. Essas elevadas taxas em bezerros recém-nascidos, ocasionadas, principalmente, por doenças infecciosas, foram e são causas de sérias perdas econômicas, representando, ainda nos dias de hoje, motivo permanente de preocupação. Os Estados Unidos da América, por exemplo, possuidores de uma bovinocultura excelentemente tecnificada, perdem mais de um milhão de dólares por ano com as despesas de tratamento dos bezerros moribundos. Na Inglaterra, os prejuízos estimados com a criação dos bezerros privados da ingestão de quantidades suficientes de colostro são bem maiores, aproximando-se de oito milhões de dólares por ano. Em nosso País, ainda não existem dados estatísticos referentes à mortalidade de neonatos por agressões patogênicas causadas por vírus, bactérias e/ou protozoários.

Sugere-se que a identificação de bezerros com níveis inadequados de imunoglobulinas colostrais poderia beneficiar o criador de bezerros, já que esses animais poderiam receber cuidados que os tornaria menos susce- tíveis às doenças infecciosas, reduzindo, conseqüentemente, o índice de mortalidade e os gastos com seu tratamento (WHITE et al., 1993).

Alguns estudos sobre o risco da ocorrência de doenças em bezerros com falha de transferência de imunidade passiva (FTIP) têm mostrado resultados alarmantes. DONOVAN et al. (1986) constataram que os bezerros que morriam por doenças infecciosas, durante as primeiras 14 semanas de vida, possuíam concentrações significantemente menores de proteínas séricas do que aqueles que sobreviviam a esse período.

HEATH (1992), após intensa pesquisa, postulou como sendo a taxa ideal um valor igual a $5,5 \mathrm{~g} / \mathrm{dl}$ de proteína total em bovinos de um rebanho, o ideal para que houvesse uma proteção satisfatória dos bezerros recémnascidos contra agentes infecciosos.

REA et al. (1996), ao estudarem uma população de bezerros com idade variando de um a oito dias observaram que a média da taxa sérica de proteína total obtida foi de 5,56 g/dl. Dos 246 bezerros estudados por esses autores, $66(27 \%)$ e $118(48 \%)$ tinham concentrações de proteínas séricas menores do que 5,0 e $5,5 \mathrm{~g} / \mathrm{dl}$, respectivamente; os bezerros que possuíam níveis séricos menores do que 4,5 g/dl apresentaram maiores riscos de saúde e de vida, com evidente aumento das taxas de letalidade e mortalidade.

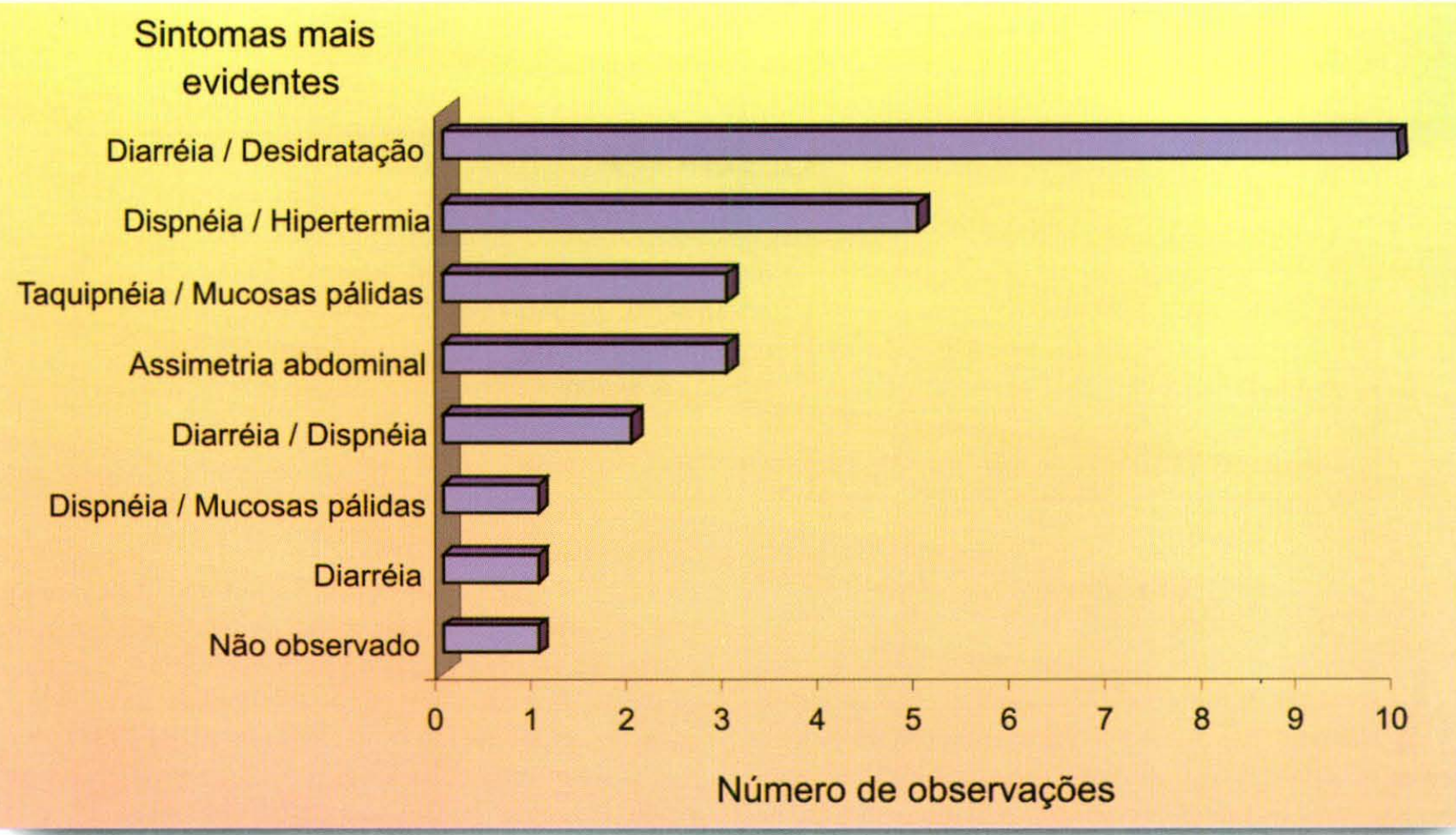

Figura 1. Principais sintomas observados em bezerros da raça Holandesa desde o nascimento até os 90 dias de idade, submetidos à ingestão natural de colostro. Araçatuba, 1998. 
SELIM et al. (1995), examinando 1.000 bezerros criados em fazendas situadas na região central da Califórnia, demonstraram a importância da transferência da imunidade passiva através de anticorpos colostrais e a relação entre a maior taxa de mortalidade e as pequenas concentrações séricas de IgG em bezerros neonatos. Das 75 mortes observadas, 31 delas ocorreram em bezerros com até 60 dias de vida, mas a maior incidência de mortalidade ocorreu antes de os bezerros alcançarem duas semanas de vida. Nesse estudo, $49 \%$ dos bezerros que necessitaram ser medicados, por estarem com diarréia e broncopneumonia, apresentavam pequena concentração de imunoglobulinas. Os autores observaram, ainda, que bezerros com teores de IgG menores do que $500 \mathrm{mg} / \mathrm{dl}$ possuíam nove vezes mais risco de morrer do que aqueles com concentrações de IgG maiores do que $1500 \mathrm{mg} / \mathrm{dl}$.

Em uma pesquisa complementar, WITTUM e PERINO (1995), reestudando as amostras de soro sangüíneo de 263 bezerros obtidas às 24 horas de vida, observaram que $25 \%$ dos bezerros que possuíam níveis inadequados de IgG ficaram doentes, enquanto que apenas 5\% dos bezerros com concentrações satisfatórias dessa fração imunoglobulínica adoeceram no mesmo período.

\section{Objetivo}

O presente trabalho teve como objetivo avaliar a importância da adequada transferência de imunidade colostral para a saúde e sobrevivência de bezerros da raça holandesa, desde o nascimento até os três meses de idade.

\section{Material e Métodos}

Foram utilizados 40 animais da raça holandesa, machos e fêmeas, que permaneceram com as mães por um período de 16 a 24 horas, ingerindo colostro "ad libitum", e que foram submetidos à avaliações clínicas periódicas, desde o nascimento até os três meses de idade. As colheitas de sangue para a obtenção de soro foram realizadas às 24 horas de vida, por punção jugular.

A proteína sérica total foi determinada pelo método do biureto, segundo GORNALL et al. (1949), modificado por STRUFALDI (1987), utilizando-se para tal um analisador bioquímico automático (Bayer - Technicom RA100 ${ }^{\text {tm }}$ system). Para a separação das frações protéicas do soro sangüíneo foi utilizado o método eletroforéti- co segundo as técnicas descritas por FRIEDMAN (1961). A leitura e o cálculo das frações separadas pela eletroforese (albumina, alfa, beta e gama globulinas) foram realizados em densitômetro (Zênite - Z30 turbo).

As taxas da imunoglobulina sérica avaliada foram determinadas por imunodifusão radial segundo a técnica de MANCINI et al. (1965), utilizando-se placas de ágar (Binding Site Kit) incorporadas com anti-soros específicos para a imunoglobulina $\mathrm{G}$ de bovinos.

A atividade sérica da gama-glutamiltransferase (GGT) foi determinada pelo método cinético colorimétrico, recomendado pela International Federation of Clinical Chemistry (IFCC), utilizando-se "kit" comercial (Boehringher Mannheim), segundo técnica modificada de SZASZ et al. (1969), em analisador bioquímico automático (Bayer - Technicom - RA100tm system).

Para a obtenção dos valores de referência dos constituintes do soro sangüíneo de bezerros com 24 horas de vida, foi realizada a estatística descritiva pela determinação dos valores de tendência central (média e mediana) e dos valores de dispersão (desvio padrão, coeficiente de variação e valores mínimo e máximo) para cada variável. Para a verificação da existência de diferenças entre os animais sadios, doentes, sobreviventes e mortos, realizou-se a análise de variância para cada variável, às 24 horas de vida. Todos os testes foram aplicados com significância de 5\% (ZAR, 1984).

\section{Resultados e Discussão}

A orientação das referências da bibliografia consultada permitiu que fosse vislumbrado o momento da estabilização dos níveis séricos da grande maioria das variáveis estudadas no presente trabalho, em que desta- 


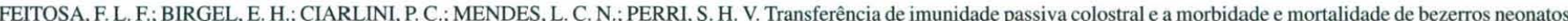

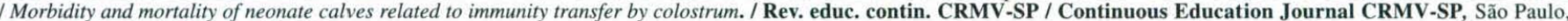
volume 4 , fascículo 2 , p. $9-15,2001$.

Tabela 2: Valores médios e respectivos desvios-padrão $(\mathrm{x} \pm \mathrm{s})$ de proteína total (PT), beta globulina (BETA), gama globulina (GAMA) e mediana da atividade de gama-glutamiltransferase (GGT) e da concentração da imunoglobulina G (IgG) no soro sangüíneo de bezerros com 24 horas de vida, dos grupos experimentais formados por animais que permaneceram saudáveis, pelos que adoeceram, sobreviveram e morreram de doenças infecciosas, durante o período experimental. Araçatuba - SP, 1998.

\begin{tabular}{|c|c|c|c|c|c|c|}
\hline GRUPOS & $\begin{array}{c}N^{0} \\
\text { Animais }\end{array}$ & $\begin{array}{c}x \pm S \\
\operatorname{PT}(g / d)\end{array}$ & $\begin{array}{c}x+s \\
\text { BETA }(g / d \text { dl) }\end{array}$ & $\begin{array}{c}x+s \\
\text { GAMA (g/dil) }\end{array}$ & $\begin{array}{l}\text { Mediana } \\
\text { GGT (UI/I) }\end{array}$ & $\begin{array}{l}\text { Mediana } \\
\text { lg (mg/dl) }\end{array}$ \\
\hline Saudáveis & 23 & $7,10 \pm 1,10 \mathrm{~A}$ & $0,90 \pm 0,30 \mathrm{~A}$ & $2,50 \pm 0,90 \mathrm{~A}$ & $772,90 \mathrm{~A}$ & $3440,50 \mathrm{~A}$ \\
\hline Doentes & 17 & $5,70 \pm 1,30 \mathrm{~B}$ & $0,80 \pm 0,30 \mathrm{~A}$ & $1,60 \pm 1,10 \mathrm{~B}$ & $295,00 \mathrm{~B}$ & $1894,00 \mathrm{~B}$ \\
\hline Sobreviventes & 29 & $7,02 \pm 0,96 a$ & $0,93 \pm 0,28 a$ & $2,51 \pm 0,82 \mathrm{a}$ & $840,55 \mathrm{a}$ & $3821,64 \mathrm{a}$ \\
\hline Mortos & 7 & $4,71 \pm 0,84 b$ & $0,57 \pm 0,19 b$ & $0,65 \pm 0,50 b$ & $105,13 b$ & $1015,00 \mathrm{~b}$ \\
\hline
\end{tabular}

*Diferenças de letras maiúsculas (saudáveis $\mathrm{x}$ doentes) e minúsculas (sobreviventes $\mathrm{x}$ mortos) indicam diferenças estatisticamente significativas $(\mathrm{p}<0,05$ )

cavam, invariavelmente, esse momento como sendo o final do primeiro dia de vida, ou seja, 24 horas após o nascimento.

O exame clínico rotineiro dos 40 animais avaliados, muitas vezes auxiliado por exames subsidiários, complementados, nos casos de evolução mortal, pela necroscopia, permitiu o diagnóstico nosológico das seguintes enfermidades: broncopneumonia, enterite infecciosa, onfalite simples e supurada, anaplasmose, hemorragia intra-abdominal, indigestão leitosa e asfixia por enforcamento. Os casos de enterite infecciosa foram observados a partir dos quatro dias de vida e acometeram o maior número de animais (10 entre 26 animais doentes, isto é, $38,46 \%$ ), sendo a enfermidade responsável pela morte de dois deles. Apesar de ter sido verificada a ocorrência de broncopneumonia em cinco animais $(19,23 \%)$ a partir dos 20 dias de vida, a taxa de mortalidade foi maior do que as determinadas por outras doenças, pois três dos cinco bezerros acometidos, morreram. Em dois bezerros neonatos, observou-se a ocorrência concomitante de broncopneumonia e diarréia (pneumoenterite), sendo que ambos morreram na evolução da enfermidade. Em três animais (11,54 \%), diagnosticou-se onfalite simples e supurada, e o mesmo número de casos de anaplasmose; no entanto, entre eles, não foi constatada a ocorrência de evolução mortal (Tabela 1).

Nove $(22,5 \%)$ dos 40 bezerros avaliados morreram antes mesmo de completarem 90 dias de vida; um índice de mortalidade menor do que os destacados por GAY et al. (1965) e BLOM (1982), mas de magnitude similar à descrita por STOTT et al. (1979). No entanto, dentre esses nove bezerros, um morreu acidentalmente por enforcamento nas correntes de contenção, e o outro, em conseqüência de um possível trauma abdominal, determinante de hemorragia interna. Indubitavelmente, como em ambos os casos o óbito não estava relacionado aos níveis de imunoglobulinas séricas, os mesmos foram excluídos do grupo de animais mortos por doenças infecciosas, quando da realização da análise estatística.

A concentração média de proteína total observada para os animais que sobreviveram até o final da parte experimental deste trabalho, foi de 7,02 $\pm 0,96 \mathrm{~g} / \mathrm{dl}$, significativamente maior do que o valor de 4,71 $\pm 0,84 \mathrm{~g} / \mathrm{dl}$, obtido no grupo de animais que morreram no decurso da pesquisa (Tabela 2).

As frações beta e gama globulínicas foram significantemente maiores nos animais que permaneceram vivos até o final do experimento (Tabela 2), fato que serviu para endossar as conclusões de DONOVAN et al. (1986) que constataram, durante as primeiras semanas de vida, uma maior mortalidade por doenças infecciosas nos bezerros possuidores de menores concentrações séricas dessas frações protéicas. Um exemplo marcante de tal conclusão foi a observação de que sete dos 40 bezerros estudados possuíam concentração sérica média da fração gama globulínicas menor do que $1,00 \mathrm{~g} / \mathrm{dl} \mathrm{e}$, entre eles, constatou-se seis $(85,7 \%)$ casos de óbito. Somente no animal que teve morte acidental por enforcamento, o valor da referida fração foi maior que $2,00 \mathrm{~g} / \mathrm{dl}$.

Os resultados obtidos demonstraram que os teores séricos de $\mathrm{IgG}$, determinados pela imunodifusão radial, foram cerca de $73,44 \%$ menores nos animais que morreram do que os valores observados para o grupo de animais que sobreviveram (Tabela 2), endossando as afirmações de INGRAM et al. (1958) e ODDE (1988). Em três animais, que morreram no transcurso da fase experimental, as concentrações séricas de IgG foram menores do que $500 \mathrm{mg} / \mathrm{dl}$ após a ingestão de colostro, comprovando relatos semelhantes feitos por SELIM et al. (1995). Entretanto, um dos animais que morreram apresentava níveis séricos de IgG iguais a $677,53 \mathrm{mg} / \mathrm{dl}$, valor situado acima do limiar estabelecido pelos pesquisadores acima mencionados, mas situado dentro da faixa de maior risco descrita por MICUNOVICK et al. (1995), que va- 


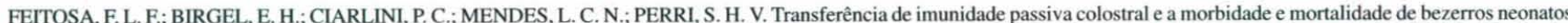

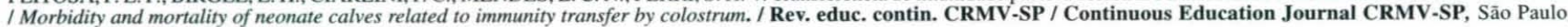

riou entre 631 e $1260 \mathrm{mg} / \mathrm{dl}$, em bezerros apresentando problemas gastrintestinais e respiratórios.

WITTUM e PERINO (1995), consideraram as concentrações séricas de IgG maiores do que $1600 \mathrm{mg} / \mathrm{dl}$ como adequadas, as concentrações que variavam de 800 a $1600 \mathrm{mg} / \mathrm{dl}$ como níveis marginais e as menores do que $800 \mathrm{mg} /$ dl como indicativas de hipogamaglobulinemia. Levando-se em consideração o referido conceito, observou-se que no grupo de bezerros que sobreviveu no período experimental desta pesquisa, apenas um animal apresentava concentração sérica de IgG menor do que o nível superior representado por $1600 \mathrm{mg} / \mathrm{dl}$, enquanto que os demais tinham concentrações de IgG maiores do que $2000 \mathrm{mg} / \mathrm{dl}$ (Tabela 3).

Os resultados obtidos nesta pesquisa permitiram que se verificasse a existência de correlação entre a pequena atividade sérica da enzima gama-glutamiltransferase e o elevado número de óbitos, pois, no grupo de animais que sobreviveu, a atividade sérica enzimática da GGT foi cerca de sete vezes maior do que a observada nos animais que morreram (Tabela 2). Oito dos 40 animais $(20 \%)$ avaliados apresentavam essa atividade menor do que $200 \mathrm{UI} / \mathrm{l}$ e, destes, sete morreram $(87,5 \%)$. Este valor de 200 UI/l foi utilizado por PERINO et al.(1993) para diagnosticar a ocorrência de falha na transferência de imunidade passiva.

Constatou-se que tanto os animais que adoeceram como os que morreram durante o período de avaliação possuíam os menores valores mínimos, bem como, as menores concentrações médias de proteína total, de fração gama globulínica, de imunoglobulina G e uma reduzida atividade da enzima gama-glutamiltransferase, quando comparados com aqueles que permaneceram sadios e sobreviveram até o final do estudo (Tabelas 2 e 4).
Tabela 3. Relação entre o número de animais doentes e mortos e os níveis de imunoglobulina $\mathrm{G}$ em 40 bezerros da raça Holandesa, adotando-se a

\begin{tabular}{|c|c|c|c|c|}
\hline $\begin{array}{c}\text { Concentração } \\
\text { de IgG }(\mathbf{m g} / \mathrm{dl})\end{array}$ & Classificação & $\boldsymbol{N}^{0}$ de Doentes & $N^{0}$ Mortes & Porcentagem \\
\hline$>1600$ & Adequado & 12 & 1 & $8,3 \%$ \\
\hline 800 a 1600 & Marginal & 1 & 1 & $100 \%$ \\
\hline$<800$ & Inadequado & 4 & 4 & $100 \%$ \\
\hline
\end{tabular}

Acreditamos que seja possível inferir ou prognosticar sobre a saúde futura e, conseqüentemente, sobre a probabilidade de morte de um determinado animal, levando-se em consideração o seu "status" imunológico às 24 horas de vida, bem como o seu grau de exposição do mesmo a agentes infecciosos presentes em um determinado ambiente. Entretanto, a confirmação veemente de que o animal com falha de transferência de imunidade passiva tornar-se-á doente, é um tanto que precipitada. Por exemplo, quando a classificação de WITTUM e PERINO (1995) foi adotada e aplicada aos dados obtidos nesse trabalho, observou-se que, dos 17 animais que adoeceram durante os três meses de vida, 12 desses possuiriam níveis adequados, enquanto apenas cinco animais teriam, às 24 horas de idade e, de acordo com tal classificação, níveis marginais e/ou inadequados de IgG para o respectivo momento (Tabela 3). Contudo, somente um dos 12 bezerros com concentrações de IgG consideradas satisfatórias morreu, enquanto que todos os animais com comprovada falha de transferência de imunidade passiva e com valores considerados marginais, sucumbiram. Dessa forma, pode-se supor que a recuperação de animais doentes que possuam níveis satisfatórios de imunoglobulinas circulantes é muito melhor do que a daqueles que não os tenham. Dos 23 bezerros sobreviventes, só um animal possuía teores de IgG tidos como marginais, enquanto os animais restantes apresentavam níveis adequados.

Tabela 4. Valores mínimos (VMi) e máximos (VMa) das concentrações de proteína total (PT), beta globulina (BETA), gama globulina (GAMA), gama-glutamiltransferase (GGT) e imunoglobulina G do soro sangüíneo de bezerros com 24 horas de vida, dos grupos experimentais formados por animais que permaneceram saudáveis, adoeceram, sobreviveram e morreram de doenças infecciosas, durante o período experimental. Araçatuba - SP, 1998.

\begin{tabular}{|l|c|c|c|c|c|c|}
\hline GRUP0S & $\begin{array}{c}N^{0} \\
\text { Animais }\end{array}$ & $\begin{array}{c}\text { VMi - VMa } \\
\text { PT (g/dl) }\end{array}$ & $\begin{array}{c}\text { VMi - VMa } \\
\text { BETA (g/dl) }\end{array}$ & $\begin{array}{c}\text { VMi - VMa } \\
\text { GAMA (g/dl) }\end{array}$ & $\begin{array}{c}\text { VMi - VMa } \\
\text { GGT (UI/) })\end{array}$ & $\begin{array}{c}\text { VMi - VMa } \\
\text { Ig (mg/dl) }\end{array}$ \\
\hline Saudáveis & 23 & $5,2-8,8$ & $0,38-1,37$ & $0,90-4,00$ & $71-2410$ & $1542,50-5371,70$ \\
\hline Doentes & 17 & $3,4-7,6$ & $0,26-1,43$ & $0,12-3,53$ & $14-1770$ & $302,75-5790,00$ \\
\hline Sobreviventes & 29 & $5,2-8,8$ & $0,38-1,59$ & $0,90-4,00$ & $71-2410$ & $1542,50-5371,70$ \\
\hline Mortos & 7 & $3,4-6,5$ & $0,26-0,79$ & $0,12-2,47$ & $14-1200$ & $302,75-3023,40$ \\
\hline
\end{tabular}




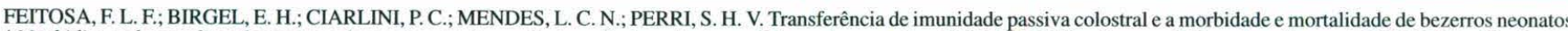

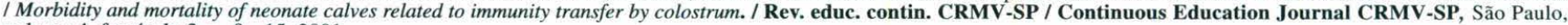
volume 4, fascículo 2, p. 9 - 15, 2001.

A grande variabilidade de conceitos apresentados pelos pesquisadores referidos na revisão de literatura, procurando estabelecer correlações entre mortalidade de bezerros e falha de transferência de imunidade passiva, reflete, de certo modo, a interferência e influência das diferentes práticas de manejo e dos diferentes níveis de exposição dos animais neonatos aos agentes etiológicos de doenças infecciosas em animais jovens. Nesse complexo biológico vital, adicionou-se a fundamental importância da quantidade de anticorpos maternais absorvidos e a especificidade do anticorpo para os agentes agressores envolvidos. Em conseqüência, a ausência de anticorpos específicos é, talvez, o principal fator para explicar a morte de alguns bezerros neonatos possuidores de concentrações adequadas de imunoglobulinas séricas. Em contrapartida, existem casos de bezerros com comprovada falha de transferência de imunidade passiva que permaneceram saudáveis, provavelmente pela pequena exposição aos agentes infecciosos e/ou por contarem com anticorpos específicos para os agentes agressores do ambiente em que viviam.

Assim sendo, a avaliação conjunta dos resultados do trabalho e os conhecimentos explicitados na literatura pertinente permitiram a afirmação de que, nem sempre, a constatação da ausência de concentrações séricas adequadas de imunoglobulinas em bezerros neonatos implicaria na ocorrência de doenças, evoluindo para um desenlace fatal. Ao contrário, esses resultados inscritos em zonas de alarme deveriam ser indicadores de risco, endossando a importância de algumas medidas de segurança, como o fornecimento de colostro de boa qualidade, no momento preciso e em quantidade suficiente para manter a higidez do plantel e favorecer a sobrevivência dos bezerros recém-nascidos, endossando as recomendações dos trabalhos de McGUIRE et al. (1976); SMITH e LITTLE (1922).

\section{Conclusão}

Este estudo confirmou que a sobrevivência de bezerros neonatos está grandemente associada a uma adequada transferência de imunoglobulinas por meio da ingestão do colostro ao nascimento e que maiores concentrações dessas proteínas acarreta, consequentemente, uma melhor proteção contra doenças infecciosas.

\section{REFERÊNCIAS}

1. BISWAL, S. P.; DUTTA, N. K.; MISHRA, P. R. Estimation of total serum protein and immunoglobulin level in neonatal calves. Indian Veterinary Journal, v. 70, n. 1, p. 7-9, 1993.

2. BLOM, J. Y. The relationship between serum immunoglobulin values and incidence of respiratory disease and enteritis in calves. Nordisk Veterinaermedicin, v. 34, n. 7-9, p. 276-84, 1982.

3. DONOVAN, G. A.; BADINGA, L.; COLLIER, R.; WILCOX, C. J.; BRAUN, R. K. Factors influencing passive transfer in dairy calves. Journal of Dairy Science, v. 69, n. 3, p.754-759, 1986.

4. FRIEDMAN, H. S. A standardized procedure for serum protein electrophoresis on cellulose acetate membrane strips. Clinica Chimica Acta, v. 6, p. 775-781, 1961.

5. GAY, C. C.; ANDERSON, N.; FISCHER, E. W.; McEWAN, A. D. Gammaglobulin levels and neonatal mortality in market calves. Veterinary Record, London, v. 77, n. 5, p. 148-49, 1965.

6. GORNALL, A. G.; BARDAWILL, C. J.; DAVID, M. M. Determination of serum protein by means of biuret reaction. Journal of Biological Chemistry, v. 177, p. 751-66, 1949.
7. HEATH, S. E. Neonatal diarrhea in calves : Investigation of herd management practices. Compendium on Continuing Education for the Practicing Veterinarian, v. 14 , n. 3, p. 385- 95, 1992.

8. INGRAM, P. L.; SHILLAM, K. W. G.; HAWKINS, G. M.; ROY, J. H. B. The nutritive value of colostrum for the calf: 14 . Further studies on the effect of antibiotics on the performance of colostrum-deprived calves. Britsh Journal of Nutrition, v. 12, n. 2, p. 203-15, 1958.

9. McGUIRE, T. C.; PFEIFFER, N. E.; WEIKEL, J. M.; BARTS$\mathrm{CH}$, R. C. Failure of colostral immunoglobulin transfer in calves dying from infectious diseases. Journal of the American Veterinary Medical Association, v. 169, n. 7, p. 713-718, 1976.

10. MANCINI, G.; CARBONARA, A. O.; HEREMANS, J. F. Immunochemical quantification of antigens by single radial immunodiffusion. Immunochemistry, v. 2, n. 3, p. 235-54, 1965.

11. MICUNOVIC, J.; ZADMIK, T.; NEMEC, M.; JAZBEC, I. Gammaglobulin status of newborn calves. Veterinarske-Novice, v. 22, n. $7 / 8$, p. $247-251,1995$. 
12. ODDE, K. G. Survival of neonatal calf. Veterinary Clinics of North America - Food Animal Practice, v. 4, n. 3, p. 501-508, 1988.

13. PERINO, L. J.; SUTHERLAND, R. L.; WOOLLEN, N. E. Serum gamma-glutamyltransferase activity and protein concentration at birth and after suckling in calves with adequate and inadequate passive transfer of immunoglobulin G. American Journal of Veterinary Research, v. 54, n. 1, p. 56-59, 1993.

14. REA, D. E.; TYLER, J. W.; HANCOCK, D. D.; BESSER, T. E.; WILSON, L.; KRYTENBERG, D. S.; SANDERS, S. G. Prediction of calf mortality by use of tests for passive transfer of colostral immunoglobulin. Journal of American Medical AsSociation, v. 208, n. 12, p. 2047-2049, 1996.

15. ROBISON, J. D.; STOTT, G. H.; DENISE, S. K. Effects of passive immunity on growth and survival in the dairy heifer, Journal of Dairy Science, v. 71, n. 5, p. 1283-1287, 1988.

16. SELIM, S. A.; SMITH, B. P.; CULLOR, J. S.; BLANCHARD, P.; FARVER, T. B.; DILLING, G.; RODEN, L.; WILGENBURG, B. Serum immunoglobulins in calves : Their effects and two easy, reliable means of measurement. Veterinary Medicine, v. 90, n. 4, p. 387-404, 1995.
17. SMITH, T.; LITTLE, R. B. The significance of colostrum to the newborn calf. The Journal of Experimental Medicine, New York, v. 36, n. 2 , p.181-198, 1922.

18. STOTT, G. H.; MARX, D. B.; MENEFEE, B. E.; NIGHTENGALE, G. T. Colostral immunoglobulin transfer in calves. I Period of absorption. Journal of Dairy Science, v. 62, n. 10, p. 1632-1638, 1979.

19. STRUFALDI, B. Prática de bioquímica clínica. São Paulo: Faculdade de Ciências Farmacêuticas da Universidade de São Paulo, 1987. 399 p.

20. SZASZ, G. A kinetic photometric method for serum gamma glutamyl transpeptidase. Clinical Chemistry, v. 15, n. 2, p. 124$135,1969$.

21. WHITE, D. G. Colostral supplementation in ruminants. Compendium of Continuing Education in Veterinary Practice, $v$. 15 , n. 2 , p. $335-342,1993$

22. WITTUM, T. E.; PERINO, L. J. Passive immune status at post partum hour 24 and long-term health and performance of calves. American Journal of Veterinary Research, v. 56, n. 9, p. 1149-1154, 1995.

23. ZAR, J. H. Biostatistical analysis. Englewood. Cliffs: Prentice-Hall, 1984. 718 p.

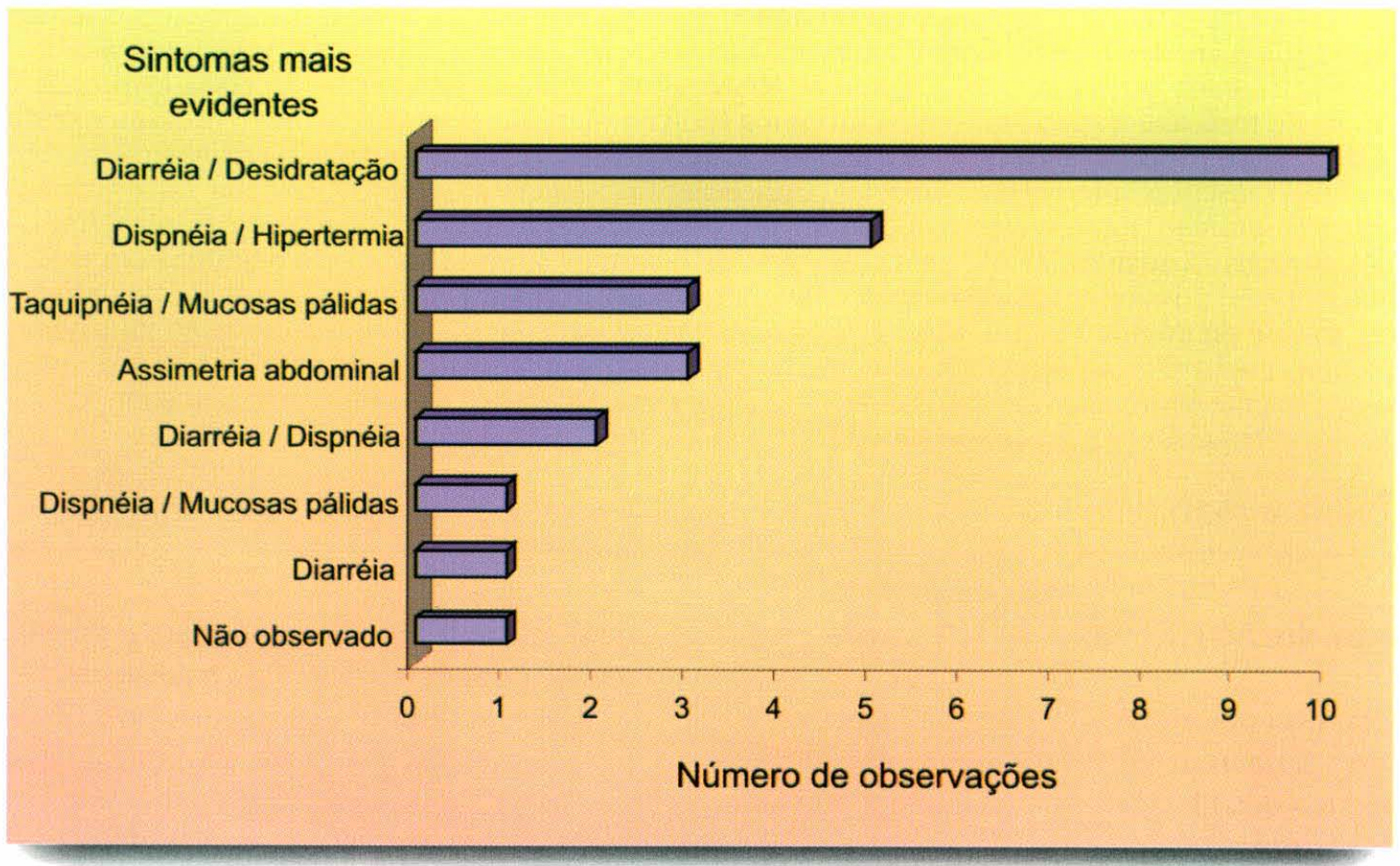

